\title{
A Facile and Low-Cost Method to Produce Ultrapure 99.99999\% Gallium
}

\author{
Kefeng Pan ${ }^{1,2}$, Ying $\mathrm{Li}^{1,2}{ }^{\text {, }}$, Jiawei Zhang ${ }^{1,2}$ and Qing Zhao ${ }^{1,2}$ \\ 1 School of Metallurgy, Northeastern University, Shenyang 110819, China; xiaopandy@126.com (K.P.); \\ zhang416940558@163.com (J.Z.); 18369904008@163.com (Q.Z.) \\ 2 Liaoning Key Laboratory for Metallurgical Sensors and Technology, Shenyang 110819, China \\ * Correspondence: liying@mail.neu.edu.cn; Tel.: +86-130-7063-9976
}

Received: 30 October 2018; Accepted: 15 November 2018; Published: 17 November 2018

\begin{abstract}
As one of the critical raw materials, very pure gallium is important for the semiconductor and photoelectric industry. Unfortunately, refining gallium to obtain a purity that exceeds $99.99999 \%$ is very difficult. In this paper, a new, facile and efficient continuous partial recrystallization method to prepare gallium of high purity is investigated. Impurity concentrations, segregation coefficients, and the purification effect were measured. The results indicated that the contaminating elements accumulated in the liquid phase along the crystal direction. The order of the removal ratio was $\mathrm{Cu}>\mathrm{Mg}>\mathrm{Pb}>\mathrm{Cr}>\mathrm{Zn}>\mathrm{Fe}$. This corresponded to the order of the experimentally obtained segregation coefficients for each impurity: $\mathrm{Cu}<\mathrm{Mg}<\mathrm{Pb}<\mathrm{Cr}<\mathrm{Zn}<\mathrm{Fe}$. The segregation coefficient of the impurities depended strongly on the crystallization rate. All observed impurity concentrations were substantially reduced, and the purity of the gallium obtained after our refinement exceeded $99.99999 \%$.
\end{abstract}

Keywords: gallium; metallurgy; recrystallization; impurity; segregation coefficient; purification method

\section{Introduction}

Gallium (Ga), one of the important raw materials used in contemporary semiconductor industry, was discovered in 1875 [1], and has been significantly utilized in the industry since the 1940s. Ga and its compounds are extensively used in advanced electronic devices [2-4], integrated circuits [5-7], and thin-film solar cells $[8,9]$ because these compounds can provide the benefits of low energy consumption and high computation speeds.

Current industrial production of low-grade (4N, 99.99\% pure) Ga has been perfected [10-12]. According to a report published by the U.S. Geological Survey (USGS) in 2015, the global demand for $\mathrm{Ga}$ is ever-increasing and is expected to increase 20-fold by 2030 compared to the yield of 275 tons in 2012 [13]. In another statistical data reported by USGS in 2018, the world low-grade primary gallium production was estimated to be 315 tons in 2017-an increase of 15\% from 274 tons in 2016. Integrated circuits accounted for $70 \%$ of domestic gallium consumption, and optoelectronic devices accounted for $30 \%$ [14]. However, even very small amounts of impurities, such as $\mathrm{Cu}, \mathrm{Pb}, \mathrm{Fe}, \mathrm{Mg}, \mathrm{Zn}$, and $\mathrm{Cr}$, which are always present in current large-scale, commercial-quality gallium, can degrade or limit the electrical properties [15]. Traditional refining methods, such as electrolysis and combined processes, have been used in the past to remove these impurities to obtain high-purity gallium [16]. These conventional methods, however, are very energy-consuming, harmful to the environment, and relatively slow. Hence, a superior purification method would be of great significance for the global semiconductor and photovoltaic industry.

Crystallization method is considered as the most promising technique for large-scale industrial production of high-purity Ga because of its simple equipment, ease of operation, and short 
production cycle. Based on the different solubility between the bulk and the contaminating elements in the liquid phase, upward directional solidification has been used to refine materials such as solar-grade silicon [17,18]. During upward directional solidification, most of the impurities with a lower segregation coefficient accumulate near the top of the ingot. Unfortunately, the low crystal growth rate usually causes visible back-diffusion in the solid phase, which reduces the purification effect [19]. In addition, low efficiency, i.e., slow growth rate, is a major problem.

In this study, continuous partial recrystallization is proposed and used to refine $4 \mathrm{~N}$ gallium to an ultrapure level ( $7 \mathrm{~N}, \geq 99.99999 \%$ pure). The refining process was designed and optimized and the purification effect, together with contributing factors like crystallization temperature, solidification rate and ratio, were investigated. The crucial segregation coefficients of the contaminating elements in gallium were also determined.

\section{Methods}

\subsection{Refining Process}

The refining process, a schematic of which is shown in Figure 1, was implemented in a custommade cylindrical polytetrafluoroethylene crystallizer with a jacket structure and an internal and external cavity.

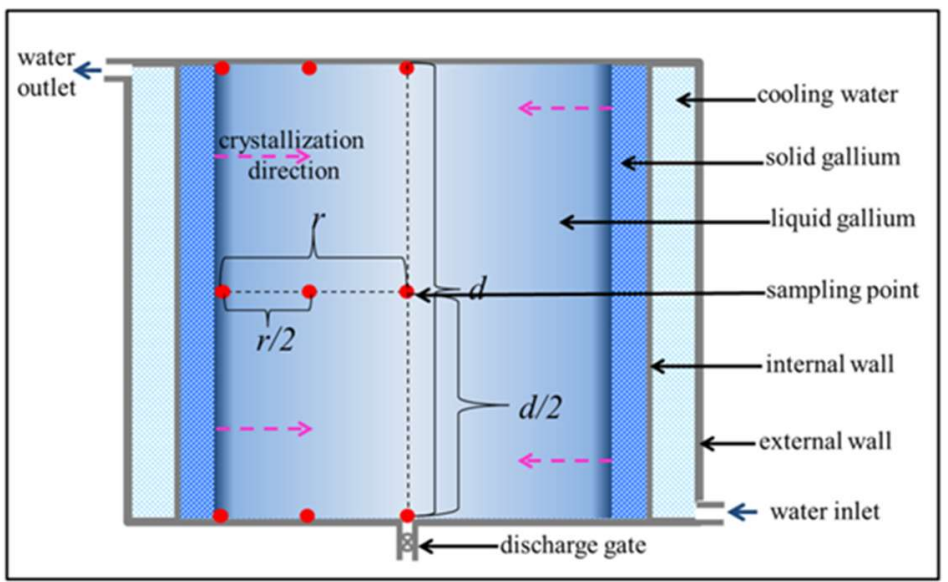

Figure 1. Schematic of the refining process, where $r$ is the distance from the solidification interface to the center of the crystallizer, and $d$ is the distance between the top and the bottom of liquid Ga.

Three kilograms of $4 \mathrm{~N}$ Ga was molten at $338.15 \mathrm{~K}$ and washed with $150 \mathrm{~mL}, 3 \mathrm{~mol} / \mathrm{L} \mathrm{HCl}$, and $\mathrm{HNO}_{3}$ for 30 min successively. In the washing process, spongy gallium was dissolved, and $2.9774 \mathrm{~kg}$ of liquid Ga was obtained; the percentage of gallium dissolved was $0.75 \%$. Then, the impurity concentrations $C_{0}$ (wt. $\%$ ) of the washed Ga were determined using glow discharge mass spectrometry (GDMS) (Evans Materials Technology (Shanghai) Co., China). Subsequently, the liquid Ga was transferred to the internal cavity. Cooling water was poured into the external cavity from the water inlet, which was located at the bottom of the crystallizer, with a $40 \mathrm{~L} / \mathrm{h}$ flow rate. The water was removed through an outlet at the top. After cooling the melted Ga to $303 \mathrm{~K}$, four types of crystal seeds, $0.5 \mathrm{~cm}$ in size, were symmetrically added along the inner wall of the inner cavity. Both temperature and flow rate of the cooling water were kept constant to allow liquid Ga to crystallize uniformly along the inner wall of the inner cavity and toward the center. When the crystallization ratio reached the preset values, the remaining liquid Ga was expelled from the discharge gate, located at the bottom center of the crystallizer, and collected as raw material for the next refining step. Subsequently, $360 \mathrm{~K}$ hot water was added to the external cavity to remelt the solid Ga that crystallized. The above crystallization process was repeated several times until the expected Ga purity was reached. 
All refining and testing were implemented in a Class 10,000 cleanroom. Acid washing was performed using spectrally pure $\mathrm{HCl}$ and $\mathrm{HNO}_{3}$ and ultrapure water with better than $16 \mathrm{M} \Omega \cdot \mathrm{cm}$ resistivity.

\subsection{Quality Test}

The refined ultrapure Ga and remaining impurities were measured using GDMS (Evans Materials Technology (Shanghai) Co., China). A well-characterized Tantalum (Ta) check sample was used to ensure that the complete GDMS system meets the basic criteria for the required analysis. An approximately $2 \mathrm{~cm} \times 0.2 \mathrm{~cm}$ pin of gallium was formed with liquid nitrogen. The glow discharge ion source was cooled to near liquid nitrogen temperature, and the sample was presputtered for $5 \mathrm{~min}$ before data acquisition began. Both data acquisition and presputtering were carried out under the same analytical conditions, and the efficiency of the ion-counting detector was checked during the analysis of the Ta Quality Control sample. Data for the gallium sample were collected until the last 3 mass fraction readings varied by no more than $20 \%$. Elements were scanned individually, with an integration time of $80 \mathrm{~ms}$. For accuracy, nine sampling points (the red dots in Figure 1) were defined to measure impurity concentration changes, while the ingot grew during the refining process.

\section{Results and Discussion}

\subsection{Flow Rate and Temperature of the Cooling Water Influence on the Refining Process}

Strict control of the solidification process during the synthesis of single crystals or polycrystalline grains with large sizes and with minimum impurities entrapped in the grain boundaries is extremely important for high-purity Ga smelting. An ideal condition is when the liquid gallium is uniformly crystallized along the inner wall of the crystallizer toward the center, and this process usually needs to be carried out in a temperature field with uniform and stable temperature gradient. For this reason, the influence of flow rate and temperature of the cooling water on the refining process was tested.

Figure 2 shows the shapes of the Ga solidification at different flow rates. It can be seen that at a flow rate of $40 \mathrm{~L} / \mathrm{h}$, the growth of Ga solidification was uniform with a direction of crystallization from the edge to the center. When the flow was changed to $60 \mathrm{~L} / \mathrm{h}$, the crystallization rate of liquid at the bottom of the crystallizer was faster than the top, and the crystal interface was rough. According to the metal crystallization theory, with the increase in cooling water flow, the overcooling degree at the bottom is greater than that in other regions and the crystallization rate is too high, resulting in excessive growth of crystals in the bottom area and uneven crystallization. In our study, at cooling water flow of $40 \mathrm{~L} / \mathrm{h}$, the growth rate on the side far away from the water inlet was far lower than that in other areas.

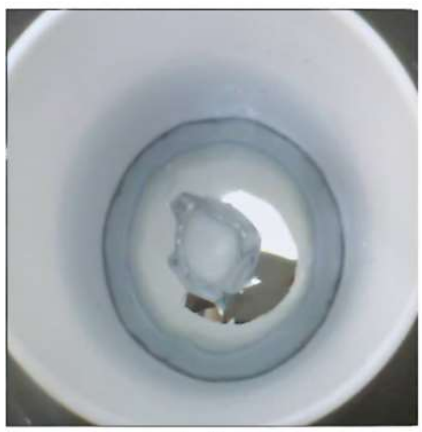

(a)

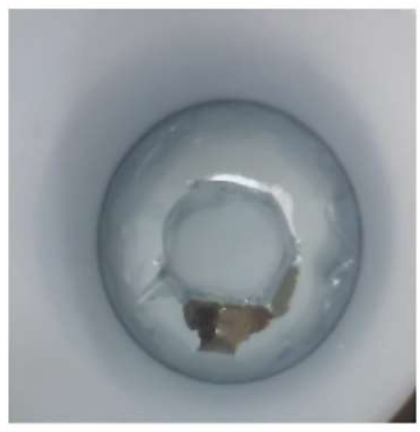

(b)

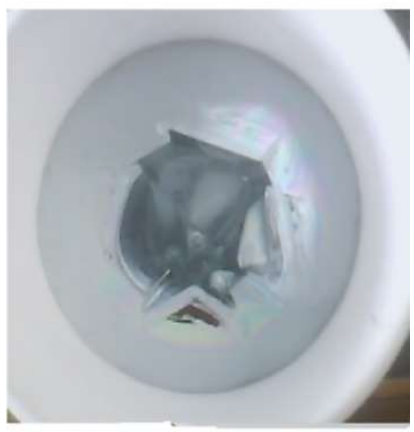

(c)

Figure 2. Shape of the solidification at different flow rates: (a) $20 \mathrm{~L} / \mathrm{h}$; (b) $40 \mathrm{~L} / \mathrm{h}$; and (c) $60 \mathrm{~L} / \mathrm{h}$ in the refining process. 
The crystallization rate $v(\mathrm{~kg} / \mathrm{h})$ was controlled by changing the temperature of the cooling water between 283.15 and $297.15 \mathrm{~K}$ (see Figure 3). It can be seen that the crystallization rate decreased gradually with increasing temperature $T(\mathrm{~K})$. The relationship between them fit well with the following linear function:

$$
v=-0.09 T+27
$$

with the linearly dependent coefficient $R^{2}=0.997$. The strong linear correlation helps to obtain an accurate solidification ratio by controlling the crystallization time during refining.

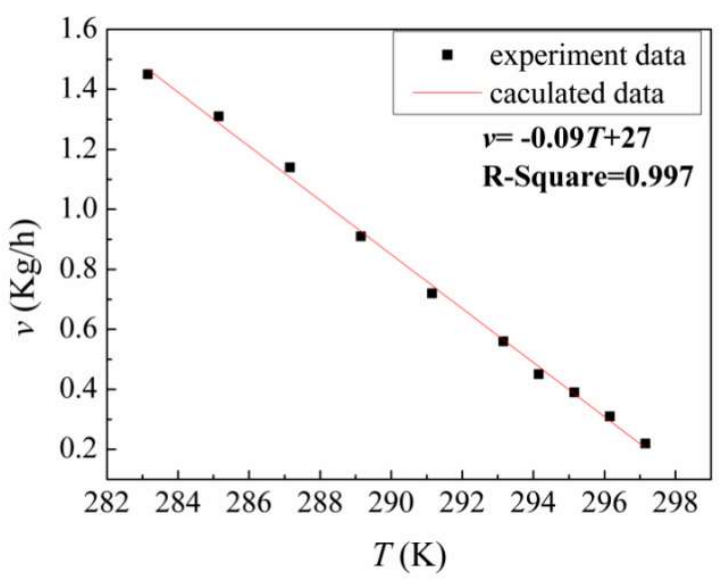

Figure 3. Crystallization rate $v$ controlled by changing the temperature $T$ of the cooling water, between $283.15 \mathrm{~K}$ and $297.15 \mathrm{~K}$. The black points represent experimental measurements, and the red line is obtained by linear fitting.

\subsection{Impurity Redistribution}

A good understanding of the regularity of the impurity redistribution during ingot growth helps fine-tune the refining process. Unfortunately, it is difficult to obtain this important information by analyzing the morphology and microstructure via SEM [17] or other direct observation methods because of the low melting point (about $303 \mathrm{~K}$ ) of Ga. Additionally, direct detection of the impurity concentrations in the growth direction is difficult. A convenient alternative is to measure the impurity concentrations in liquid $\mathrm{Ga}, C_{l}(\mathrm{wt} . \%)$, at different solidification ratios $g(\%)$ during the refining process. Then, the impurity concentrations in solid $\mathrm{Ga}, \mathrm{C}_{s}(\mathrm{wt} . \%)$, can be derived from the mass conservation law using the following equation:

$$
C_{s}=\left(C_{0}-C_{l} \cdot(1-g)\right) / g
$$

The $C_{s}$ profiles of the main impurities- $\mathrm{Fe}, \mathrm{Pb}, \mathrm{Zn}, \mathrm{Mg}, \mathrm{Cu}$, and $\mathrm{Cr}-$ for a solidification ratio range of $5-95 \%$ are shown in Figure $4 \mathrm{a}$. The impurity concentrations increased exponentially with increasing solidification ratios, and the trend lines were almost identical for the six elements. The results indicated that, during the refining process, the freshly solidified layer, formed at the solid/liquid interface with the Ga ingot that grows continuously from the internal wall to center of the crystallizer, transferred the impurities to the adjacent liquid layer. This way, an enriched liquid layer with impurities was created. In addition, these condensed impurities diffused towards the liquid bulk, which resulted in a progressive increase of impurities in the liquid. The difference between the impurity concentrations in solid and melt can be determined by the known equilibrium segregation coefficient, which is defined as

$$
K=C_{s} / C_{l}
$$

for a given temperature [20]. Based on the radial exponential redistribution of each impurity in solid Ga, the effect of the solidification ratio on the removal efficiency of these impurities is defined as follows: 


$$
R \%=\left(\left(C_{0}-C_{s}\right) / C_{0}\right) \cdot 100 \%
$$

When we investigated this ratio, as shown in Figure $4 \mathrm{~b}$, we found that $R \%$ for each element decreased with increase in solidification ratio, and Fe and $\mathrm{Zn}$ changed faster than the other four elements: Fe (86.5-25.1\%), Zn (92.5-55.5\%), Cr (96.9-76.2\%), Pb (98.3-85\%), Mg (99.2-91.1\%), and Cu (99.6-94.6\%). The $\mathrm{R} \%$ profiles also indicated that the order of the removal radii was $\mathrm{Cu}>\mathrm{Mg}>\mathrm{Pb}>\mathrm{Cr}$ $>\mathrm{Zn}>\mathrm{Fe}$. Based on the above results, the refining method used $R \%=70 \%$ for the first two runs of the recrystallization process and $R \%=85 \%$ for the third.

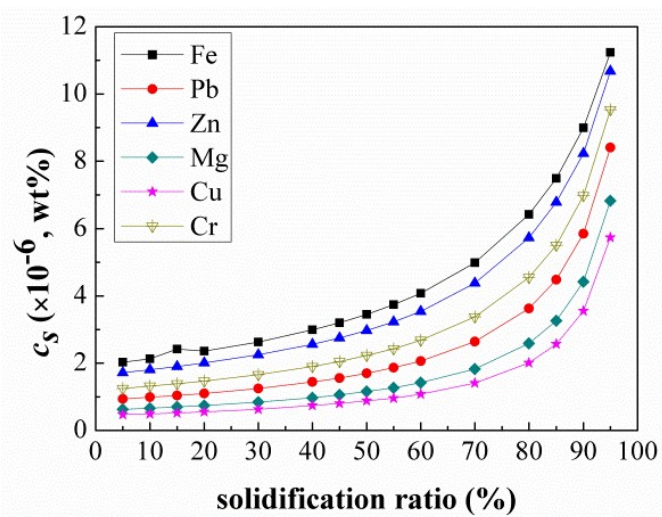

(a)

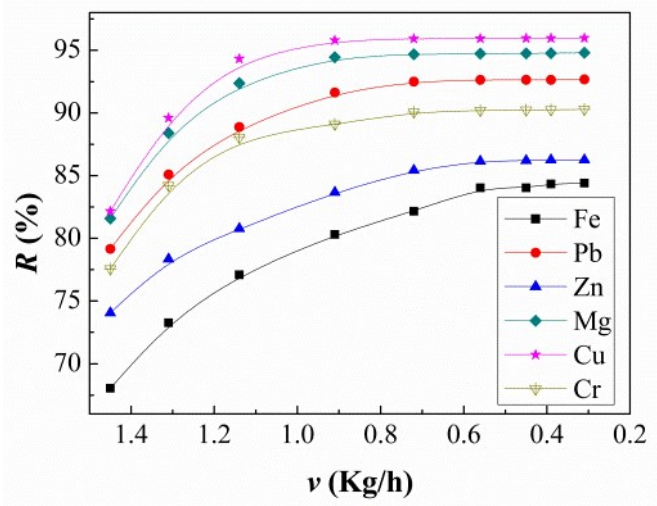

(b)

Figure 4. (a) Regularity of element impurity redistribution. $C_{S}$ is the impurity concentration in solid Ga. (b) Removal efficiency for each impurity's $R \%$ at different solidification ratios.

\subsection{Experimental Segregation Coefficient}

The effect of crystallization rate $v$ on the removal ratio for the impurities was investigated for a solidification ratio of $20 \%$ (see Figure 5). The removal ratio for each element increased as the crystallization rate decreased to $0.39 \mathrm{~kg} / \mathrm{h}$. The removal ratio reached a maximum and remained stable, which indicated that the parameter of $v$ also played an important role in the refining process.

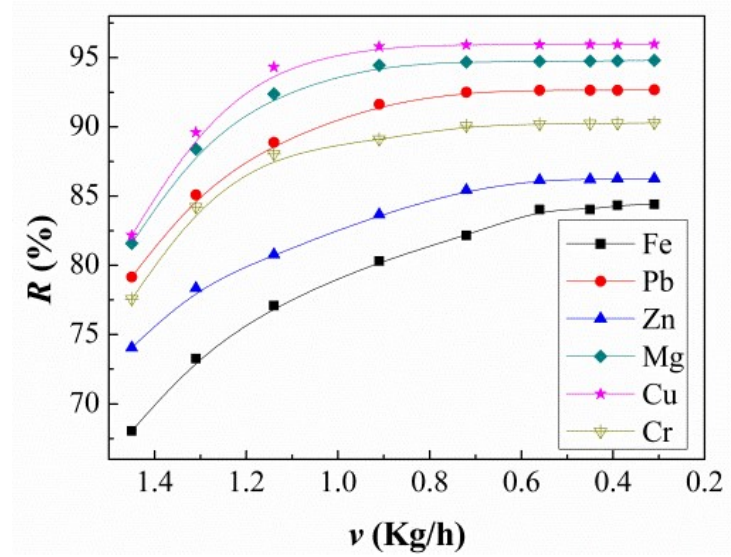

Figure 5. Effect of solidification rate $v$ on the removal ratio for the impurities $R \%$.

The experimentally obtained segregation coefficients for each impurity were estimated as described in Reference [21] using the formula

$$
K_{\text {exp }}=C_{s} / C_{l}
$$

to study the reasons for this effect (see Figure 6a). As $v$ decreased, the values for all six tested elements decreased exponentially in a crystallization rate range of $0.3-1.5 \mathrm{~kg} / \mathrm{h}$. Moreover, the three elements Fe, 
$\mathrm{Pb}, \mathrm{Zn}$ and other group of $\mathrm{Cr}, \mathrm{Mg}$, and $\mathrm{Cu}$ showed a similar trend, with $\mathrm{Fe}(0.27-0.13), \mathrm{Pb}(0.17-0.06)$, $\mathrm{Zn}(0.22-0.11), \mathrm{Cr}(0.19-0.08), \mathrm{Mg}(0.15-0.04)$, and $\mathrm{Cu}(0.15-0.03)$. Interestingly, the $K_{\text {exp }}$ values for different elements exhibited the same crystallization rates in the order $\mathrm{Cu}<\mathrm{Mg}<\mathrm{Pb}<\mathrm{Cr}<\mathrm{Zn}<\mathrm{Fe}$, which corresponded to the order of the removal ratios (see Figure $6 \mathrm{~b}$ ). This correlation indicated that the different removal efficiencies between different impurities were caused by the segregation coefficients in liquid Ga. Furthermore, the smaller the $K_{\exp }$, the better was the removal coefficient.

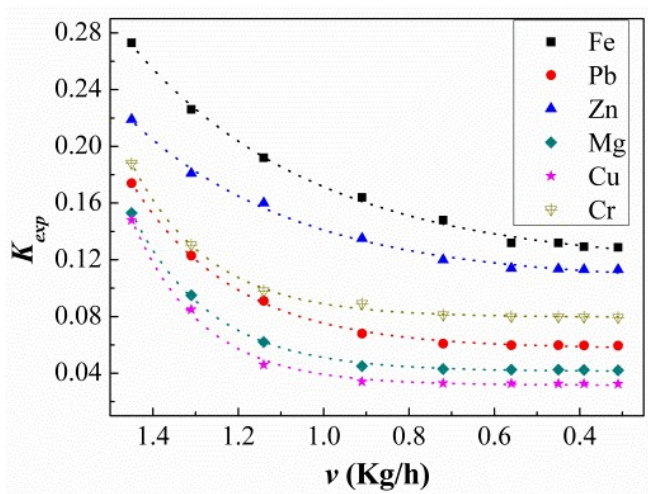

(a)

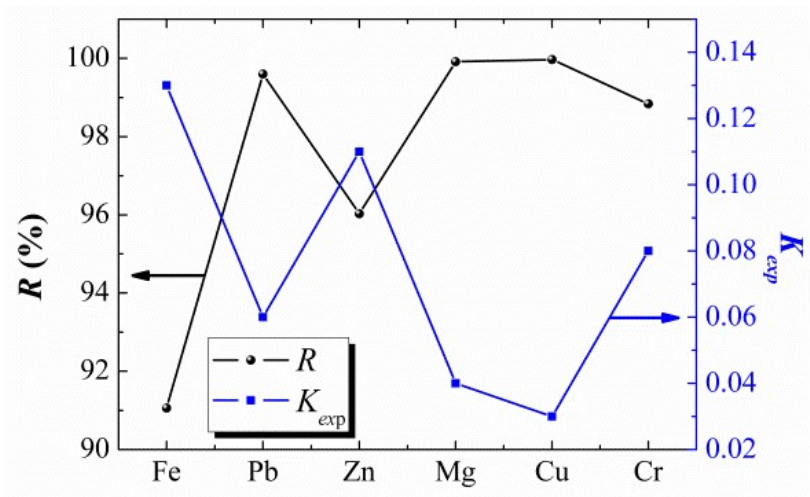

(b)

Figure 6. (a) Effect of solidification rate $v$ on the experimental segregation coefficient $K_{\text {exp }}$.

(b) Relationship between the removal ratio for the impurities $R \%$ and the segregation coefficient $K_{\exp }$.

\subsection{Quality of Ultrapure Gallium}

Based on the above results, $3 \mathrm{~kg}$ of raw Ga was refined with a crystallization rate of $0.39 \mathrm{~kg} / \mathrm{h}$. The impurity concentration for each element and the purity of Ga before and after the refining process is shown in Table 1. All six tested impurity concentrations could be reduced substantially. The highest removal ratio of $93.79 \%$ was obtained for $\mathrm{Cu}$, where the content decreased from $107 \times 10^{-6}$ to $0.22 \times 10^{-6}$ wt. $\%$. The lowest removal ratio was $93.79 \%$ (for Fe), were the concentration decreased from $15 \times 10^{-6}$ to $0.93 \times 10^{-6} \mathrm{wt}$. $\%$. After the refining process, $1.264 \mathrm{~kg}$ Ga with a purity of $99.9999958 \%$ was obtained, and all measured impurity concentration were reduced to very low levels. The remaining $1.735 \mathrm{~kg}$ Ga could be used as starting materials for the next refining process.

Table 1. Impurity concentration $\left(\times 10^{-6}\right.$, wt.\%) and purity of Ga during and after refining.

\begin{tabular}{cccccccc}
\hline Impurity & $\mathbf{F e}$ & $\mathbf{P b}$ & $\mathbf{Z n}$ & $\mathbf{M g}$ & $\mathbf{C u}$ & $\mathbf{C r}$ & Purity \% \\
\hline Before refining & 15 & 56 & 24 & 76 & 107 & 40 & 99.9938 \\
After refining & 0.93 & 0.68 & 1.05 & 0.34 & 0.22 & 0.97 & 99.9999958 \\
Removal ratio (\%) & 93.79 & 98.78 & 95.64 & 99.55 & 99.79 & 97.58 & - \\
\hline
\end{tabular}

\section{Conclusions}

The optimized partial recrystallization route showed a strong purification effect: $99.99999 \%$ pure Ga was produced using little energy and a relatively simple process with the solidification ratio of $70 \%$ for the first two runs and $85 \%$ for the third run at the crystallization rate of $0.39 \mathrm{~kg} / \mathrm{h}$. During the refining process, the impurity concentrations increased exponentially with increasing solidification ratio, and the order of the removal ratio was $\mathrm{Cu}>\mathrm{Mg}>\mathrm{Pb}>\mathrm{Cr}>\mathrm{Zn}>\mathrm{Fe}$. This order corresponded to the order of the experimental values for segregation coefficient for each impurity: $\mathrm{Cu}<\mathrm{Mg}<\mathrm{Pb}<\mathrm{Cr}<$ $\mathrm{Zn}<$ Fe. All tested element concentrations were reduced to very low levels, which means this novel refining method can open new doors to produce ultrapure gallium at a commercial scale. 


\section{Patent}

This work was awarded a patent for invention (CN201510198211.5) by national intellectual property administration, PRC.

Author Contributions: K.P. and Y.L. conceived and designed the experiments; K.P., J.Z. and Q.Z. performed the experiments; K.P., Y.L., J.Z. and Q.Z. analyzed the data and wrote the paper.

Funding: This research was funded by [National Natural Science Foundation of China] grant number [51834004, 51774076 and 51704063] and [Fundamental Research Funds for the Central Universities] grant number [N172507011].

Acknowledgments: Thanks Evans Materials Technology (Shanghai) Co., China for providing the GDMS testing service.

Conflicts of Interest: The authors declare no conflict of interest.

\section{References}

1. Moskalyk, R.R. Gallium: The backbone of the electronics industry. Miner. Eng. 2003, 16, 921-929. [CrossRef]

2. Colantonio, P.; Giannini, F.; Giofrè, R.; Piazzon, L. Increasing Doherty amplifier average efficiency exploiting device knee voltage behavior. IEEE Trans. Microw. Theory Tech. 2011, 59, 2295-2305. [CrossRef]

3. Yoon, J.S.; Yang, J.Y.; Lee, J.M.; Hong, S.J.; Hong, H.S. A development of the LED TMGa precursor reuse technology. Mater. Lett. 2013, 93, 153-156. [CrossRef]

4. Kim, I.; Kivisaari, P.; Oksanen, J.; Suihkonen, S. Diffusion-drivens charge transport in light emitting devices. Materials 2017, 10, 1421. [CrossRef] [PubMed]

5. Oon, H.S.; Cheong, K.Y. Recent development of gallium oxide thin film on GaN. Mater. Sci. Semicond. Process. 2013, 16, 1217-1231. [CrossRef]

6. Liu, S.; Sweatman, K.; McDonald, S.; Nogita, K. Ga-Based Alloys in Microelectronic Interconnects: A Review. Materials 2018, 11, 1384. [CrossRef] [PubMed]

7. Yang, X.F.; Zhang, C.Y.; Zhang, Z.B.; Pun, E.Y.B.; Zhang, D.L. Low-loss Ga:Er:LiTaO3optical waveguide for integrated optics. Mater. Lett. 2018, 227, 199-201. [CrossRef]

8. Li, P.W.; Zhou, W.H.; Hou, Z.L.; Wu, S.X. Synthesis of CuIn xGa 1-xSe 2 nanocrystals for potential thin film photovoltaic application under air condition. Mater. Lett. 2012, 78, 131-134. [CrossRef]

9. Wei, Y.; Zhuang, D.; Zhao, M.; Zhang, N.; Yu, X.; Sun, R.; Zhang, L.; Lyu, X.; Peng, X.; Wei, J. Fabrication of wide band-gap $\mathrm{CuGaSe2solar}$ cells for tandem device applications by sputtering from a ternary target and post selenization treatment. Mater. Lett. 2018, 230, 128-131. [CrossRef]

10. Zhao, Z.; Yang, Y.; Xiao, Y.; Fan, Y. Recovery of gallium from Bayer liquor: A review. Hydrometallurgy 2012, 125, 115-124. [CrossRef]

11. Swain, B.; Mishra, C.; Kang, L.; Park, K.S.; Lee, C.G.; Hong, H.S. Recycling process for recovery of gallium from GaN an e-waste of LED industry through ball milling, annealing and leaching. Environ. Res. 2015, 138, 401-408. [CrossRef] [PubMed]

12. Liu, F.; Liu, Z.; Li, Y.; Wilson, B.P.; Lundström, M. Recovery and separation of gallium(III) and germanium(IV) from zinc refinery residues: Part I: Leaching and iron(III) removal. Hydrometallurgy 2017, 169, 564-570. [CrossRef]

13. Lu, F.; Xiao, T.; Lin, J.; Ning, Z.; Long, Q.; Xiao, L.; Huang, F.; Wang, W.; Xiao, Q.; Lan, X.; et al. Resources and extraction of gallium: A review. Hydrometallurgy 2017, 174, 105-115. [CrossRef]

14. Ober, J.A. Mineral Commodity Summaries 2018; U.S. Geological Survey: Reston, VA, USA, 2018.

15. Meyer, S.; Wahl, S.; Molchanov, A.; Neckermann, K.; Möller, C.; Lauer, K.; Hagendorf, C. Influence of the feedstock purity on the solar cell efficiency. Sol. Energy Mater. Sol. Cells 2014, 130, 668-672. [CrossRef]

16. Greber, J.F. Gallium and Gallium Compounds. Kirk-Othmer Encycl. Ind. Chem. 2000. [CrossRef]

17. Huang, F.; Chen, R.; Guo, J.; Ding, H.; Su, Y. Removal of metal impurities in metallurgical grade silicon by cold crucible continuous melting and directional solidification. Sep. Purif. Technol. 2017, 188, 67-72. [CrossRef]

18. Wen, S.; Jiang, D.; Shi, S.; Tan, Y.; Li, P.; Gu, Z.; Zhang, X. Determination and controlling of crystal growth rate during silicon purification by directional solidification. Vacuum 2016, 125, 75-80. [CrossRef]

19. Wen, S.; Jiang, D.; Li, P.; Tan, Y. Back diffusion of iron impurity during silicon purification by vacuum directional solidification. Vacuum 2015, 119, 270-275. [CrossRef] 
20. Martorano, M.A.; Neto, J.B.B.F.; Oliveira, T.S.; Tsubaki, T.O. Refining of metallurgical silicon by directional solidification. Mater. Sci. Eng. B Solid-State Mater. Adv. Technol. 2011, 176, 217-226. [CrossRef]

21. Huang, S.; Ma, W.; Wei, K.; Li, S.; Morita, K. A model for distribution of aluminum in silicon refined by vacuum directional solidification. Vacuum 2013, 96, 12-17. [CrossRef]

(c)

(c) 2018 by the authors. Licensee MDPI, Basel, Switzerland. This article is an open access article distributed under the terms and conditions of the Creative Commons Attribution (CC BY) license (http:/ / creativecommons.org/licenses/by/4.0/). 